\title{
Informar ou Determinar? - Liberdade de Imprensa, Propaganda Política e Jornalismo Político.
}

\section{To Inform or To Determine? - Freedom of Press, Political Propaganda and Political Journalism.}

\author{
Vitor Barletta Machado ${ }^{1}$ \\ Katia Mika Nishimura ${ }^{2}$ \\ Bianca Monsores Gomes Brandão ${ }^{3}$ \\ Camila de Souza Braz \\ Cristiane Arantes Castro Rodrigues ${ }^{3}$ \\ João Paulo Cordeiro dos Santos da Conceição ${ }^{3}$
}

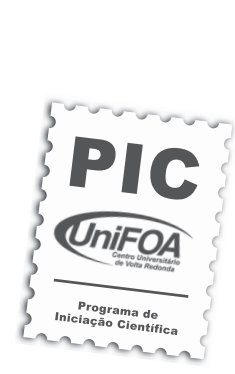

\author{
Palavras-chave \\ Liberdade de \\ imprensa \\ Eleições \\ Manipulação \\ Rede Globo
}

\section{Resumo}

O presente artigo discute, a partir dos resultados de uma pesquisa de Iniciação Científica, realizada durante o segundo semestre de 2010, a questão da relação entre a produção da informação e a escolha do eleitorado brasileiro. $\mathrm{O}$ objetivo da pesquisa consistia em avaliar se alguns dos principais telejornais brasileiros adotavam posturas políticas deliberadas em suas matérias, procurando influenciar a decisão de voto da população. A partir da observação e acompanhamento, durante todo o período da campanha eleitoral, de três telejornais da Rede Globo: Jornal Hoje, Jornal Nacional e Jornal da Globo, selecionada por ser a emissora que ainda apresenta os maiores índices de audiência e por seu envolvimento em polêmicas eleitorais no passado recente, o grupo de pesquisa avaliou a ocorrência de situações que configurassem favorecimento ou desfavorecimento a algum candidato. Os resultados da pesquisa não apontaram situações em que se observasse uma tomada explícita de posicionamento político. O levantamento e a discussão da bibliografia temática apontam conclusões que coincidiram com as alcançadas em nossas observações, de que ainda que as mídias atuem como agentes políticos partidários, isso não basta para provocar alterações nas intenções de voto. $\mathrm{O}$ artigo também avança em algumas reflexões preliminares sobre os impactos das novas formas de comunicação no contexto político contemporâneo.

\section{Abstract}

This article presents the results of a Scientific Initiation project achieved during the second half of 2010. Our objective was to evaluate whether some of the major Brazilian news television programs adopt deliberate political postures in their articles, trying to influence the voting decision of the population. We chose three news programs from Rede Globo: Jornal Hoje, Jornal Nacional e Jornal da Globo, because the channel still has the highest ratings and for its involvement in controversial election in the recent past. The research team followed these news programs throughout the campaign period, assessing the occurrence of situations that represent favor or disadvantage to any candidate. In parallel to these activities we made a thematic bibliographic research of the literature which showed conclusions that coincided with the ones reached in our observations, that even if the media act as agents of political parties that is not enough to cause changes in voting intentions. The observations of the group on news programs did not find any situations that could denote an explicit political stance taken. The article also advances on some preliminary thoughts on the impacts of the new forms of communication in the contemporary political context.
\end{abstract}

Key words

Freedom of the press

Elections

Manipulation

Rede Globo
Artigo

Original

Original

Paper

Recebido em 05/2012

Aprovado em 08/2012

\footnotetext{
${ }^{1}$ Orientador, Professor Dr. nos cursos de Comunicação Social, Direito e Serviço Social - UniFOA

${ }^{2}$ Professora Dra. dos cursos de Serviço Social e Direito. Nucleadora de Ciências Sociais Aplicadas do NUPE/PROPPE - UniFOA

${ }^{3}$ Aluno do curso de Comunicação Social - UniFOA
} 


\section{Introdução}

Retratando o processo que culminou com o estabelecimento do governo republicano no Brasil, o historiador José Murilo de Carvalho apresentou uma interessantíssima reflexão sobre uma frase de Aristides Lobo, defensor da República, escrita em artigo publicado logo após os acontecimentos de 15 de novembro de 1889: "O povo assistiu àquilo bestializado, atônito, surpreso, sem conhecer o que significava.". Lobo criticava na carta à própria condução do movimento, caracterizado como majoritariamente militar e sem participação popular. Carvalho argumenta em seu trabatho que a população do Rio de Janeiro da época, palco dos acontecimentos da implantação da República no Brasil, estava acostumada com certa "carnavalização do poder", ou seja, pela realização de grandes eventos e de muito barulho para comunicar a todos o que havia acontecido:

O povo sabia que o formal não era sério. Não havia caminhos de participação, a República não era para valer. Nessa perspectiva, o bestializado era quem levasse a política a sério, era quem se prestasse à manipulação. Num sentido talvez ainda mais profundo que o dos anarquistas, a política era tribofe. Quem apenas assistia, como fazia o povo do Rio por ocasião das grandes transformações realizadas a sua revelia, estava longe de ser bestializado. Era bilontra. (CARVALHO, 1996, p. 160)

E ser bilontra é ser malandro, gozador. A frase de Aristides Lobo expressa uma postura que ainda se encontra presente em diversas análises políticas, particularmente daquelas que procuram mostrar que o povo não sabe $o$ que acontece ao seu redor e é, por conta disso, facilmente manipulado pelos interesses dos grupos dominantes. A análise de Carvalho procura mostrar justamente o oposto, que havia da parte do povo a percepção muito clara de que a política era um jogo de interesses que se processava alheio aos seus próprios, daí seu aparente distanciamento. Aristides Lobo era político, defensor da República e mantinha uma coluna no jornal Diário Popular, no qual era colaborador. Utilizava, portanto, do espaço que dispunha na mídia de sua época para divulgar seus ideais. Possuía o perfil do que é chamado de "formador de opinião" (COIMBRA, 2007), da pessoa que atua em sociedade, auxiliando no desenvolvimento da reflexão pública. Seu incômodo com a reação popular ao movimento que havia ajudado a preparar revela, contudo, um desalento que é bastante atual, que é o do real alcance das propagandas e do jornalismo político na definição dos rumos de nossa história.

A mídia possuí tal poder? E se possuí, é realmente esse o papel que deve desempenhar? Ela deve ser a porta-voz de interesses declaradamente partidários? Pode apresentar como informação aquilo que se configura como uma determinação de "como as coisas devem ser"?. Mobilizados por essas questões e pela discussão sobre qual seria o papel exercido pelos meios de comunicação no Brasil nas disputas políticas contemporâneas, sua eficiência e no modo como a informação é produzida para o grande público, desenvolvemos tal reflexão.

Para entender as relações entre a produção da informação e a conduta do eleitorado nacional, a resposta precisaria ser buscada nos veículos de maior circulação e que alcançam um público também maior. A maior parte da população brasileira não acompanha o noticiário político através dos meios escritos, mas sim, pela televisão e rádio. A mídia escrita, caracterizada nos grandes jornais e revistas em suas versões impressas e eletrônicas, não responderia à nossa principal inquietação, o impacto dessas informações no grande público, justamente por não o atingirem ${ }^{1}$.

Optamos então por focalizar os telejornais da maior audiência. A escolha recaiu principalmente sobre a emissora de maior audiência, a Rede Globo, optando-se pelos seguintes telejornais: Jornal Hoje, Jornal Nacional e Jornal da Globo. Estávamos assim cobrindo os principais jornais veiculados pela emissora durante o dia, acompanhando o almoço, o jan-

${ }^{1}$ Pesquisa do Datafolha (2010) indicou que 65\% das pessoas utilizam principalmente a TV para obter informações sobre as eleições, mas ela foi lembrada por $88 \%$ da pessoas como fonte de dados sobre o processo eleitoral. 
tar e o início da madrugada dos brasileiros. A sistemática adotada na observação dos telejornais foi a de tomar notas e, quando possível, salvar as notícias através do site da Globo na Internet, sempre que identificássemos algum possível posicionamento favorável ou desfavorável à algum candidato.

Ficamos atentos para palavras que expressassem valoração e depreciação, para o posicionamento adotado pelos jornalistas. Feitas tais anotações, realizávamos encontros do grupo de pesquisa para discutirmos os dados selecionados e avaliá-los coletivamente. E se em eleições anteriores prevaleceu uma percepção dos pesquisadores sobre a mídia no Brasil de posicionamento e favorecimento político de determinados candidatos ${ }^{2}$, descobrimos que não podemos repetir tal análise integralmente para as eleições de 2010, pelo menos no que diz respeito aos telejornais estudados nesta pesquisa.

O acompanhamento cotidiano dos telejornais foi também complementado por consultas ao site de relacionamentos Twitter, no qual as notícias, principalmente as entrevistas com os candidatos, eram rapidamente comentadas pelos internautas. A rede social revelou-se um meio interessante de se avaliar o impacto causado pelo noticiário em, pelo menos, uma certa parcela da população. Tal parcela não é representativa de todo o eleitorado nacional, conforme veremos, mas, muitas vezes, vinculada a uma candidatura específica, que serve como meio para se avaliar as informações veiculadas pelos telejornais.

\section{O Estado e o controle da informação}

Os vínculos entre o controle da informação e o poder político não são características exclusivas da contemporaneidade. Podemos encontrar os indicativos de tais vínculos em antigas civilizações, como a romana:
Em Roma, tudo se organizava em torno da vontade de fazer da comunicação social uma das figuras centrais da vida cotidiana. A arquitetura das cidades, notadamente a instituição dos fóruns, trazia nela essa vontade. As praças centrais, sempre barulhentas e animadas, cadinho da vida política e social, também haviam existido na Grécia. (BRETON, PROULX, 2006, p. 30)

Sem nos aprofundarmos demasiadamente em tal paralelo, ressalta-se aqui, contudo, que um dos principais fatores diferenciadores que podemos destacar de nosso tempo para as épocas anteriores é ausência de meios de comunicação de massa a qual fazia com que a oralidade prevalecesse. Mesmo a palavra escrita tinha alcance limitado ${ }^{3}$ e, na maioria das vezes, se rendia ao interesse do estado ou organismos religiosos. Por muitos séculos, a comunicação coletiva esteve vinculada à segurança do Estado e proteção das instituições que atuavam ao mesmo tempo preservando e limitando o acesso geral ao conhecimento. Acreditava-se que ao se controlar a informação que chegava ao povo mantinham-se mais facilmente as relações hierárquicas entre dominantes (Estado/Igreja) e dominados (povo).

Durante a Idade Média, percebemos as mesmas relações entre comunicação, informação e conhecimento. A comunicação pública era quase que exclusivamente exercida pelo Estado que dessa maneira monopolizaram o processo, sendo ainda muito restrito o número de pessoas capazes de ler e escrever.

No século XV, temos a ocorrência da chamada revolução dos tipos móveis que, além de estruturar a imprensa, permitiu a disseminação de mais informação em menos tempo. As novas tecnologias de impressão se expandiram rapidamente pela Europa e criaram um novo paradigma na difusão da palavra escrita, além de estabelecerem um novo relacionamento entre povo e informação, já que a informação passou a durar mais e a chegar mais longe. 
Toda essa "revolução" do conhecimento acabou quebrando a hegemonia da Igreja e do Estado na reprodução das ideias e mensagens, sendo que mesmo as tentativas de se barrar a circulação da informação mostraram-se ineficazes, estimulando a circulação ilegal das mesmas. Estávamos em plena reflexão de que as mídias seriam determinantes ao influenciarem o comportamento humano, de modo que, tomando posse delas, o controle da própria sociedade seria estabelecido.

A partir da revolução industrial, os meios de comunicação, principalmente os jornais, ganham força e seu desenvolvimento passa a ser mais acelerado, tanto na sua distribuição como na sua diagramação e acessibilidade. No século XVIII, os meios de comunicação começaram a se desvincular do governo, em forma de panfletos satíricos que criticavam explicitamente o regime absolutista então vigente e seus agentes.

Os autores de tais panfletos, quando identificados, eram severamente punidos. O movimento do Iluminismo, que criou novas perspectivas e faz o horizonte de ideais se ampliar, exprimiu suas críticas a tal regime através da imprensa clandestina, normalmente financiada pela burguesia insatisfeita com os monarcas absolutos. Mas agora, na contemporaneidade, a comunicação e as formas de realizá-la são diversas, e qualquer controle que se pretenda tornou-se mais problemático. A expansão da internet, da telefonia móvel, das páginas de relacionamento, reconfiguraram a dinâmica do compartilhamento da informação e tornou praticamente impossível o controle centralizado da mesma.

Martín-Barbero (2003) acredita que a mídia no Brasil deve ser estudada de forma diferenciada graças ao desacerto existente entre o Estado e a Nação, visando posicioná-la como mediadora dessa relação. Destaca seu papel no governo autoritário de Getúlio Vargas (19371945), em um contexto no qual o ditador utilizava a mídia para difundir seu discurso de massa, ao mesmo tempo em que atuava construindo uma identidade nacional.
A mídia cumpria então o papel de ensinar as pessoas a serem brasileiras, retratando o país em suas diversidades regionais. Diversos temas foram abordados para atingir esses fins, entre eles o samba e o futebol. Este, sendo o esporte mais popular entre os brasileiros, era usado por um governo que constantemente precisava falar ao seu público. Assim, diversos eventos de futebol eram usados como palco de discursos políticos em que, além de falar às pessoas, procurava passar um sentimento de nação. Muitos campeonatos foram organizados visando estabelecer maior integração entre futebol/povo e povo/nação, e a presença da mídia foi decisiva neste processo.

A campanha Brasil na Copa era noticiada e comentada ao vivo pelo rádio, e o governo se manifestava várias vezes por meio desse meio de acordo com o avanço da nossa seleção no Campeonato Mundial ${ }^{4}$. Além disso, utilizou-se outros meios, como a censura dos meios de comunicação, o controle dos sindicatos e as perseguições políticas. O DIP (Departamento de Imprensa e Propaganda) empenhava-se para fazê-lo simpático às massas e difundir os ideias do governo e suas realizações. Getúlio acabou consolidando-se no poder com o apoio popular, mas não somente por conta de todo aparato midiático até aqui mostrado. Seu governo também entregou aos trabalhadores brasileiros a Consolidação das Leis do Trabalho (CLT), que retirou milhares de trabalhadores de condições aviltantes de trabalho e remuneração. As imagens construídas através das propagandas oficiais eram corroboradas por medidas de alcance popular e que atendiam a anseios legítimos da população.

O fim da Segunda Guerra Mundial (19391945) trouxe a derrubada do Nazi-Fascismo na Europa, contando com a participação do Exército brasileiro. O Estado Novo perdia suas forças e a falta de democracia cobrava seu preço do governo Vargas. Em outubro de 1945, um movimento militar retirou Getúlio Vargas do poder ${ }^{5}$.

Outro período em que a mídia foi amplamente utilizada pelo governo foi o que se iniciou em abril de 1964, estabelecendo uma

\footnotetext{
${ }^{4}$ É a fase de profissionalização do futebol brasileiro, conforme Rodrigues (2004): “A fase do início do profissionalismo, datada, na literatura oficial, de 1933 a 1950, caracteriza-se pela regulamentação do futebol como profissão através da legislação social e trabalhista do governo Vargas (1930-1936).” (2004, p. 273).

${ }^{5}$ Não abordaremos aqui o segundo período de governo de Vargas, marcado pelo seu suicídio, por escapar demais do propósito da discussão.
} 
Ditadura Militar que se estendeu pelos próximos 20 anos. A censura foi uma grande aliada dos ditadores militares, sofrendo os meios de comunicação e a indústria cultural uma intensa intervenção dos seus agentes. As notícias que seriam exibidas pelos jornais eram avaliadas, assim como a música popular, o cinema e a televisão. Nada que se opusesse ao governo vigente ou à imagem que pretendia construir, poderia torna-se público.

Compositores como Chico Buarque de Hollanda, Geraldo Vandré e Caetano Veloso foram perseguidos e exilados. A decretação do Ato Institucional número 5 (AI-5), estabeleceu definitivamente a censura no Brasil, bem como a prisão de quaisquer opositores do governo sem direito de Habeas Corpus.

E foi cerca de um ano após o início da Ditadura que surgiu a TV Globo, em 1965, contando com apoio dos militares e apoiando o regime. O Jornal Nacional começou em 1969, um ano após a promulgação do AI-5, tornando-se um tipo de "porta-voz da ditadura", costumava mostrar o mundo em caos enquanto o Brasil, sob o controle dos militares, estava seguro. A emissora ajudou a divulgar o programa Brasil Novo, recalcou crises, sempre moldando a realidade aos interesses da Ditadura.

Apesar de todo aparato repressivo, a Ditadura foi enfraquecendo, tanto pela ação daqueles que sempre se opuseram a ela como pelos problemas econômicos que se acumulavam com o crescimento da inflação. A própria imprensa já começava a revelar casos de corrupção.

Quando o povo clamou, nas ruas, pelo retorno de seus direitos, culminando no grande movimento das Diretas Já, nem mesmo a Rede Globo pôde continuar negando as transformações que se anunciavam, sugerindo mais uma vez que o poder controlador da mídia possui limites que precisam ainda ser melhor compreendidos. O processo de redemocratização foi lento, com início em 1974 e conclusão apenas em 1985 com a eleição de Tancredo Neves, também apoiada por Roberto Marinho, marcando o fim do autoritarismo.
A Rede Globo, contudo, manteve papel de destaque nos eventos políticos do Brasil pós-ditadura. Após apoiar a eleição ainda indireta de Tancredo Neves, demonstrou também sua preferência ao candidato Fernando Collor quando das primeiras eleições diretas à presidência. $\mathrm{O}$ caso mais flagrante foi o da edição do último debate entre Collor e Lula para o Jornal Nacional, sugerindo uma vitória do primeiro (AZEVEDO, 2006). Mas se em sua eleição Collor contou com o apoio da mídia não o pôde durante a campanha pelo seu impeachment. Acuado por acusações de corrupção o então presidente entrou em rede nacional no horário nobre da televisão pedindo que os brasileiros fossem trabalhar vestidos de verde e amarelo no dia seguinte, em sinal de patriotismo e de apoio ao governo. Obteve como resposta ruas tomadas por pessoas vestidas de preto, principalmente de jovens estudantes que configuraram o que ficou conhecido como movimento dos Caras Pintadas ${ }^{6}$. A própria mídia, inclusive a Rede Globo, abandona seu apoio ao governo Collor, já então extremamente criticado pela condução da política econômica iniciada com o confisco dos depósitos em bancos no país.

\section{A mídia e seus interesses políticos}

A televisão é um meio de comunicação bastante novo, ainda mais se considerarmos a existência milenar das várias formas de escrita e que, antes de sua existência, o rádio e o cinema já eram utilizados como meios para a propaganda política. No Brasil, a primeira emissora, a TV Tupi, foi inaugurada em 18 de setembro de 1950, com um horário reduzido de funcionamento diário e contando principalmente com artistas e profissionais anteriormente envolvidos com programas de rádio. Desde então, a televisão foi ganhando um espaço cada vez maior, retirando parte do prestígio do rádio, sem eliminar sua importância ${ }^{7}$. A atração exercida pelas imagens foi certamente

\footnotetext{
${ }^{6}$ Vestidos de pretos, mas com os rostos pintados de verde e amarelo.

${ }^{7} \mathrm{O}$ rádio ainda possui um grande papel na divulgação de informações em nossa sociedade. Ele permite que a pessoa escute as notícias enquanto realiza outras atividades, como por exemplo os trabalhos domésticos, na construção civil ou enquanto dirige um veículo. Pesquisa do Datafolha (2010) aponta o rádio como o terceiro meio de comunicação mais citado (52\%) para a obtenção de informações sobre as eleições.
} 
uma das armas para a sedução da televisão sob o público. Uma pesquisa da Eletrobrás sobre os hábitos de consumo de energia revelou que a TV estava presente em $97,1 \%$ das residências brasileiras, seguida pela geladeira presente em $96 \%$ das casas, enquanto $32,2 \%$ dispunham de computadores e $23,8 \%$ de acesso à internet (G1, 2007).

A Rede Globo enfatiza a credibilidade de seu jornalismo e o papel que exercem no fortalecimento da democracia ${ }^{8}$, mas ao contrário das mídias e redes utilizadas na internet, a televisão é um meio informativo com uma via única, não permitindo, portanto, o debate imediato sobre o que é transmitido ${ }^{9}$,ou seja, o confronto de opiniões, condição necessária para a vivência da democracia.

Concentrando-nos no contexto eleitoral, enfocado em nossa pesquisa, vemos que as redes de televisão promovem debates políticos, argumentando que o eleitor poderá então analisar a postura dos candidatos, visualizando suas expressões a cada pergunta feita, os gestos realizados, sua confiança ou falta dela. Mas, hoje, todos esses elementos podem ser previamente treinados por equipes de profissionais, visando justamente que o candidato se torne mais atraente para os eleitores. Tal realidade torna fundamental que o público realize, cada vez mais, uma análise mais detida das informações que recebe dos veículos de mídia. É significativa a reflexão de Jesus Martín-Barbero:

O marketing pretende racionalizar as variáveis para controlar as reações do público, mas eu acredito que isso está empobrecendo a capacidade mediadora dos meios de comunicação e não estou certo de que isso está produzindo um negócio maior. Eu continuo defendendo, com um conceito brasileiro, que a mídia tem brechas. Ainda que tentem racionalizar os meios de marketing, a influência sobre as pessoas, o que elas veem na TV, o que elas pensam a partir do que veem na TV, ou o que escutam no rádio, ou leem nos jornais, tudo isso nunca vai ser controlado. Não que não haja certo nível de controle, há sim, mas o controle nunca será na mesma medida em que os comerciantes acham que controlam. Como um velho ditado que diz que os professores fingem que ensinam e os alunos fingem que aprendem. Acho que existe um pouco disso na relação da mídia com as pessoas. (MARTÍN-BARBERO, 2003)

O autor sugere então que a mídia realmente tenta criar uma opinião em seu público, mas que tal processo é muito mais complexo, não existindo mesmo a possibilidade de pensarmos em um quadro de controle total, em que as pessoas estariam somente reproduzindo as vontades previamente elaboradas pelos que controlam os veículos da mídia e da política. Podemos pensar aqui, novamente, no caso do debate entre Lula e Collor em 1989 na Rede Globo. O quanto tal manipulação das informações afetou ou não o resultado daquele pleito ainda permanece como uma questão a ser melhor pesquisada, mas a diferença pequena de votos entre os candidatos, cerca de $6 \%$ dos votos válidos, é um indicativo de que algo pode ter mudado, como podemos ver na seguinte análise:

Havia uma tendência de aproximação entre os dois candidatos e no dia do debate eles estavam a apenas $1 \%$ de diferença. Com este resumo do debate exibido na sexta-feira, a pesquisa do sábado mostrou uma abertura de diferença e no domingo a diferença que era de $1 \%$ apareceu como de $4 \%$. (MATHEUS, 1993)

Pesquisa de Coimbra (2007) sobre o impacto da mídia no pleito presidencial de 2006 nos apresenta dados que reforçam a percepção de Matheus. Coimbra afirma que a influência da mídia pôde ser sentida apenas temporariamente entre o grupo de eleitores que afirmaram ter baixo interesse em política, que eram, portanto, "menos interessados e menos informa-

\footnotetext{
${ }^{8}$ Ali Kamel, diretor-executivo do jornalismo da Rede Globo, escreve frequentemente defendendo a credibilidade do trabalho que realizam e o papel fundamental da imprensa na manutenção da democracia (KAMEL, 2007a; 2007b).

${ }^{9}$ Mesmo em programas que abrem espaço para a participação dos telespectadores, seja através do telefone ou de blogs, somente as mensagens selecionadas pela emissora serão divulgadas.
} 
dos" (COIMBRA, 2007, p. 206). Somente para tal grupo de eleitores, que foram identificadas oscilações na intenção de voto, no caso entre Lula e Alckmin, coincidindo com a divulgação de denúncias contra o governo petista na mídia. Mas, tal oscilação foi pequena e, ao final, tais eleitores voltaram a votar em Lula. Nos grupos de eleitores que afirmaram ter alto, médio ou nenhum interesse por política não houve tal oscilação das intenções de voto. A reflexão sugere então que o impacto da mídia somente poderá ser decisivo de algum modo se o cenário eleitoral estiver extremamente equilibrado, mas também se as informações chegarem ao público poucos dias antes da realização da eleição, tal como ocorreu em 1989.

\section{O telejornalismo da Rede Globo nas eleições presidenciais de $\mathbf{2 0 1 0}$}

Apresentamos o resultado do acompanhamento realizado junto aos telejornais da Rede Globo, de agosto até outubro de 2010, abarcando o primeiro e o segundo turno. Procuramos observar a adoção de uma linguagem oral ou corporal que pudesse indicar um posicionamento político específico na condução dos telejornais, sem que, contudo, tenhamos elaborado um conjunto de palavras, gestos e expressões a serem buscadas, dado o fato de que cada telejornal possui um formato diferente, inclusive quanto à postura dos seus apresentadores, direcionado aos públicos também diversos que os acompanham.

Começando pelo Jornal Hoje da Rede Globo, veiculado no horário do almoço de segunda-feira a sábado, temos o caso de um telejornal feito em formato mais informal, empregando-se, inclusive, uma linguagem coloquial, em que os apresentadores, Evaristo Costa e Sandra Annenberg, procuram se apresentar de maneira mais descontraída e próxima do público, alternando o noticiário político e econômico com uma pauta de amenidades e dicas de manutenção familiar.

Durante o período de nossa pesquisa, as informações políticas veiculadas pelo Jornal Hoje visavam à exposição dos posicionamentos dos candidatos e á divulgação das pesquisas de intenção de votos. Na abordagem dos candidatos, não foi identificada a adoção de linguajar ou postura que denotasse favorecimento explícito para qualquer dos candidatos, nem também que indicassem a existência de medidas deliberadas de desfavorecimento. $\mathrm{O}$ Jornal Nacional, conduzido pelo casal Willian Bonner e Fátima Bernardes, seguiu a mesma tendência verificada no Jornal Hoje. Sendo o principal telejornal da emissora, bem como o de maior audiência, apresenta uma maior quantidade de matérias políticas e econômicas, conduzidas pelos âncoras com uma postura e ambiente diversos do jornal do meio-dia. É o espaço empregado preferencialmente para a divulgação das grandes matérias e "furos" jornalísticos. Talvez por conta justamente de seu passado polêmico, na eleição de 1989, o cuidado no emprego das palavras, gestos e expressões também foi verificado no Jornal Nacional.

Os mesmos cuidados foram percebidos no Jornal da Globo conduzido então por Willian Waack e Cristiane Pelajo, que encerra a noite na emissora, mas com algumas situações que precisaram ser discutidas dentro do grupo que conduziu esta pesquisa. Elas envolveram as entrevistas realizadas com os candidatos José Serra e Dilma Rousseff ainda durante o período de propaganda para o primeiro turno das eleições de 2010. Rousseff foi entrevistada no dia 30 de agosto e pareceu, a um dos membros do grupo de pesquisa, que as perguntas feitas, e mesmo o tom geral da entrevista, foram mais suaves do que poderiam ter sido. Os assuntos gerais giraram ao redor do passado da então candidata, ex-guerrilheira e presa política no período da Ditadura Militar, e sobre a possível composição dos quadros de seu governo, diante da pressão de aliados por cargos. A candidata desviou-se das perguntas ao afirmar que era cedo para discutir tais temas, uma vez que as eleições ainda não haviam ocorrido. Abordou-se também a acusação feita pelo PSDB (de José Serra) de que membros do PT (de Rousseff) estariam envolvidos na produção e compra de um dossiê contra o seu candidato. A resposta foi somente a de que as acusações careciam de fundamento e de que ela jamais esteve envolvida em qualquer tipo de caso de corrupção. Outro ponto foi sobre a concentração de cargos no governo para membros do PT durante o governo de Luís Inácio da Silva, ao que Rousseff somente disse que em seu governo a competência da 
pessoa é que seria determinante para as indicações e não o pertencimento político.

A entrevista com José Serra ocorreu no dia 31 de agosto. As principais perguntas foram feitas sobre a própria campanha do candidato, a qual havia apresentado uma queda nas intenções de voto, após o início da propaganda eleitoral na televisão. Serra argumentou que as pesquisas refletem somente o momento em que foram realizadas e que certamente iriam mudar. Waack então comentou sobre o fato de que algumas personalidades do PSDB ainda não haviam aparecido publicamente apoiando sua candidatura, ao que Serra respondeu ressaltando que onde quer fosse sempre havia alguém demonstrando seu apoio. As demais questões versaram sobre o programa de governo do candidato, que tentou destacar suas diferenças.

O problema debatido no grupo de pesquisa surgiu com a comparação da postura do jornalista Willian Waack nas duas entrevistas, considerada mais suave com Rousseff e mais incisiva com Serra. A questão foi posta para avaliação e as entrevistas, já amplamente comentadas nas redes sociais, revistas.

A conclusão geral do grupo foi de que a avaliação sobre o posicionamento do jornalista variava conforme a preferência de quem a realizava. Blogs, Twiters e comunidades diversas, que eram frequentadas por simpatizantes do candidato do PSDB, avaliavam a postura de Waack como imparcial. Comunidades e blogs favoráveis à então candidata Rousseff percebiam o oposto, justamente um favorecimento à José Serra. Alguns exemplos desses posicionamentos são ilustrativos. O Blog Escrevinhador, de Rodrigo Vianna, elogiou a entrevista ${ }^{10}$, mas criticou a postura de Serra que não teria respondido às perguntas difíceis e utilizado o espaço para atacar os "blogs sujos", que estariam atacando sua campanha. $\mathrm{O}$ texto do Escrevinhador foi reproduzido com as devidas referências no Blog do Amoralnato ${ }^{11}$, que se apresenta como totalmente independente e conduz uma campanha contra a Rede Globo.
O Blog do Celso Jardim chegou a sugerir que a entrevista de Waack com Serra havia sido previamente ensaiada ${ }^{12}$. Em outros, como no blog Professor Hariovaldo Almeida $\mathrm{Prado}^{13}$, encontramos ataques generalizados à mídia que teria sido "comprada" pelos membros do PT. O retorno à entrevista revelou perguntas que foram complicadas para ambos os candidatos, versando sobre os temas que circulavam no noticiário de então, em que tanto Rousseff quanto Serra aproveitaram para fortalecer suas posições políticas.

Uma vez analisadas tais perspectivas e sendo as entrevistas novamente avaliadas, o grupo acabou consolidado na conclusão de que existem elementos nas falas ocorridas durante $\mathrm{o}$ Jornal da Globo que podem apoiar as duas interpretações, tanto de favorecimento como de desfavorecimento de ambos os candidatos, mas, que a sua percepção varia também em conformidade com o posicionamento político de quem assiste. Prevaleceu então a perspectiva geral de que, nas últimas décadas, o próprio telejornalismo sofreu alterações em função dos desdobramentos de casos como os das eleições de 1989 aqui já apresentados. Se é verdade que podemos encontrar indícios de preferência partidária nos telejornais analisados, também é verdade que se vislumbrou a existência de um padrão geral de tratamento aos então candidatos.

A população que assiste aos noticiários não o faz simplesmente de maneira passiva. Ainda que se possam negar as manipulações políticas ao redor do debate entre Collor e Lula em 1989, o fato é que a edição veiculada pelo Jornal Nacional levantou tal discussão. E a corrupção no governo de Collor e seu posterior impeachment certamente contribuíram para fortalecer tal percepção. Podemos perceber que nem a mídia e nem os eleitores podem mais ser compreendidos simplesmente através do esquema manipuladores/manipulados ${ }^{14}$.

Os dois candidatos principais foram questionados no jornal em temas que já vinham sendo divulgados pelos diferentes meios

\footnotetext{
${ }^{10}$ Disponível em: <http://www.rodrigovianna.com.br/geral/jose-serra-volta-a-atacar-blogs-sujos.html>.

${ }^{11}$ Disponível em: <http://amoralnato.blogspot.com/2010/09/da-serie-diz-me-com-quem-rastejas.html>.

${ }^{12}$ Disponível em: <http://blogdocelsojardim.blogspot.com/2010/08/willian-waak-ensaia-com-serra.html>.

${ }_{13}$ Disponível em: <http://www.hariovaldo.com.br/site/2009/12/11/midia-golpista-e-tendenciosa-tenta-enganar-incautos-edistorcer-a-realidade/>; $\quad<$ http://www.hariovaldo.com.br/site/2010/10/02/agora-so-a-fraude-impede-a-vitoria-de-serra-noprimeiro-turno/>.
} 
de comunicação, ambos também o utilizaram para defenderem suas propostas e ressaltarem suas críticas. Não se trataram, portanto, de perguntas sobre as quais eles não tinham qualquer conhecimento, que tivessem sido elaboradas para deixá-los sem resposta. Denúncias como a produção de dossiês e a quebra de sigilo fiscal de familiares do candidato Serra não afetaram o resultado eleitoral antecipado pelas pesquisas de opinião, apesar de terem sido fartamente veiculadas nas mídias, sugerindo que as informações divulgadas não foram simplesmente incorporadas como verdades absolutas pela população, mas que as mesmas passaram por um processo de avaliação.

Devemos considerar que ainda que as notícias tenham credibilidade, ou seja, que as pessoas acreditem que reproduzem a verdade, não bastam para provocar uma alteração da intenção de voto, que é regulada por diversos fatores além das informações transmitidas pela televisão. $\mathrm{O}$ fato de um candidato aparecer vinculado a esquemas suspeitos não transforma os seus oponentes em bastiões da honestidade e probidade administrativa.

Há que se ressaltar que a imagem geral dos políticos no Brasil é majoritariamente negativa além do fato de existir certa tolerância à corrupção entre nossa população, conforme podemos verificar em pesquisa do IBOPE (2006), que revelou que 59\% dos eleitores aceitavam que familiares e conhecidos fossem escolhidos para os cargos de confiança e outros $43 \%$ não se importavam que viagens oficiais sejam utilizadas para o lazer pessoal e familiar do político. A mesma pesquisa indicou que $70 \%$ dos entrevistados acreditavam que o brasileiro, em geral, age visando somente seu próprio benefício, mas que também seria um povo trabalhador $(80 \%)$.

Sobre nossos políticos, $73 \%$ os descreveram como preguiçosos; $87 \%$ afirmaram que atuam somente em benefício próprio, sendo ainda classificados como egoístas (81\%) e desonestos $(82 \%)$. Ao se comparar a honestidade de nossos políticos com os de outros países $36 \%$ acharam que são igualmente honestos enquanto $45 \%$ que eles são mais desonestos que a média mundial.
Como se percebe, o retrato geral dos políticos sugere que acusações de corrupção não são realmente vistas com surpresa pela população, tratando-se de um comportamento em certa medida esperado, ainda que não desejado. Mas é interessante verificar que a mesma pesquisa indicou que $82 \%$ dos entrevistados consideram que fazer uma ligação clandestina de eletricidade é um ato grave e inaceitável, do mesmo modo que apresentar um atestado médico falso no trabalho ou na escola (78\%), mas, o nepotismo, crime tipicamente político, foi assim classificado por $56 \%$ das pessoas, revelando a existência de uma tolerância maior com tal prática quando comparada às duas primeiras.

Não temos elementos para avaliar os motivos de tal diferença, mas ela certamente é indicativa de que as relações das pessoas com a política são mediadas por valores diversos. Tais informações reforçam também a percepção do nosso grupo de pesquisa de que diante de um quadro geral no qual os políticos são vistos com desconfiança, atribuir o favoritismo a um candidato e a perseguição aberta a outro pela mídia pode ser muito mais o resultado de um posicionamento político específico da pessoa que emite tal opinião do que uma situação real de manipulação.

\section{Mídia Partidária e Eleições 2010}

As observações anteriores não servem, contudo, para negar a existência de posicionamentos políticos na mídia nacional. Nas eleições de 2010, tivemos a adesão pública de alguns desses meios de comunicação às campanhas dos candidatos principais, que mesmo não tendo sido objetos de reflexão sistemática pelo grupo de pesquisa, merecem aqui um breve destaque. O primeiro a tomar tal atitude foi o jornal $O$ Estado de S. Paulo ${ }^{15}$, que revelou em editorial sua opção pela candidatura de José Serra, sendo seguido, alguns dias depois, pela revista Carta Capital, que declarou apoio à candidatura de Dilma Rousseff. O editorial em que o Estadão defende abertamente o voto em José Serra foi publicado em 25 de setembro de 2010 pelo jornal com o sugestivo

\footnotetext{
${ }^{14}$ Mais adiante trataremos do caso do jornal O Estado de S. Paulo e da revista Carta Capital, que assumiram posicionamentos políticos específicos em seus editoriais. Veremos que o impacto dos posicionamentos desses meios de comunicação no eleitorado é questionável bem como o impacto em sua própria credibilidade.
} 
título de "O mal a evitar", empregando termos como "facção" ao falar sobre o PT durante o governo Lula, que é chamado de "chefão" em alusão óbvia aos filmes da trilogia de " $O$ Poderoso Chefão", sobre uma família de mafiosos. O editorial da revista foi publicado em 30 de setembro, com o título sintético de "Por que apoiamos Dilma", que tinha um tom crítico ao PSDB, comparado ao pensamento udenista, mas sem estender as mesmas como críticas diretamente à José Serra. Em ambos os veículos aparecia o discurso sobre a defesa do caminho que acreditavam ser melhor para o Brasil. Uma diferença a ser destacada é que enquanto o jornal se dedicou muito mais a atacar o governo Lula e o PT, não chegando nem a mencionar o nome de Dilma, identificada genericamente como uma candidata inventada para representar o ex-presidente, a revista optou por enfatizar suas críticas ao governo Lula, mas também a qualificar Dilma como sendo a melhor preparada. Procedendo assim, a revista mostrava sua posição mas também tentava esvaziar o sentido de denúncia do editorial do Estadão, pois a Carta Capital também levantou críticas ao governo Lula ao mesmo tempo em que the reconhecia os avanços. A disputa de política partidária eleitoral através da mídia havia sido então publicamente definida em contornos diretos.

Nas reações dos leitores de ambos encontramos semelhanças, havendo os elogios pela abertura política e as críticas quanto à imparcialidade. Mas independente da posição adotada pela Carta Capital e pelo Estadão, que está longe de ser vista como consenso, fica a questão, ainda por ser resolvida em novas pesquisas, sobre os impactos de tal decisão no público de leitores. Devem-se verificar os impactos na credibilidade desses meios de comunicação, na medida em que eventuais futuras críticas ou elogios a políticos específicos poderão ser consideradas como demonstrações de posicionamento e interesse político e não como informação e cunho jornalístico. Interessante que tanto o jornal como a revista tenham justificado tal medida justamente dentro do interesse de se fortalecer o nosso sistema democrático, estabelecendo um debate franco e aberto, sem disfarces sobre as suas motivações. Ainda mais interessante é saber que o perfil do leitor do Estadão e da Carta Capital é o mesmo:

- $\quad 87 \%$ dos leitores do Estadão e $85 \%$ da Carta Capital são das classes A e B;

- $\quad 63 \%$ dos leitores do Estadão ${ }^{16}$ e $68 \%$ da Carta Capital possuem nível superior ${ }^{17}$.

A análise do perfil simples dos leitores nos mostra que tanto a revista quanto o jornal atendem e disputam um mesmo público, as classes A e B, pessoas com alto poder aquisitivo, que tiveram acesso à escolaridade superior. Um público normalmente apresentado como formador e opinião, significando não somente que possuem acesso à informação, mas que são consultados sobre questões diversas por diferentes pessoas. Tão parecidos no perfil socioeconômico, tão distantes na preferência político-partidária.

Se fosse verdadeiro que a mídia exerce um papel absoluto nas definições de voto, ao ficarmos diante da constatação de que foi justamente na mídia escrita que tivemos uma opção política claramente exposta, pelo menos nos dois casos aqui apresentados, fato não verificado nas mídias televisivas pesquisadas, poderíamos acabar inclinados à suposição de que seriam justamente os extratos tidos como mais esclarecidos os mais influenciados pelos meios de comunicação. Tal percepção seria, contudo, tão equivocada quanto a que aqui já foi descartada sobre o papel predominante da mídia na definição do voto. Estamos diante de um confronto de ideias e valores que não põem ser explicados facilmente em esquemas genéricos sobre o poder de manipulação da mídia. Já vimos que tais práticas existem, mas que somente podem provocar mudanças no cenário eleitoral em contextos muito específicos.

\footnotetext{
${ }^{15}$ Conhecido como Estadão.

${ }^{16}$ Mídia Kit O Estado de S. Paulo 2007. Disponível em: <http://www.grupoestado.com.br/midiakit/estadao/index. asp?Fuseaction=Perfil>. Acesso em: $01 \mathrm{dez} .2011$.
}

${ }^{17}$ Mídia Kit Carta Capital 2011. Disponível em: < http://www.slideshare.net/cartacapital/mdia-kit-carta-capital-2011economist>. Acesso em: 01 dez. 2011. 


\section{Conclusão - As novas mídias e a política}

O estudo realizado ao longo desta pesquisa não pretende certamente ser definitivo sobre a questão da influência da mídia na decisão do voto. Tratamos aqui de realizar uma observação preliminar, pautada pela discussão bibliográfica, avançando na melhor compreensão das relações existentes entre a política partidária, os produtores da informação e o público que a consome. Fica claro que tais relações são muito mais complexas e dinâmicas do que a lógica da manipulação da opinião pública pelos meios de comunicação tradicionalmente define.

Os estudos aqui analisados, em paralelo com nossas observações sobre a mídia televisiva, revelam que as matérias veiculadas nos meios de comunicação não são incorporadas como verdades absolutas e isentas de interesses pela população.

A divulgação de informações aparece como um campo de disputas entre interesses diversos do mesmo modo que o embate político entre partidos e candidatos. $\mathrm{O}$ discurso da mídia- ao redor de sua própria autonomia, isenção e liberdade - surge aqui como um entre tantos outros discursos que pretendem construir a autoimagem daquele que o pronuncia.

Em um terreno de disputa no mercado dos leitores mais do que efetivamente ser é necessário reafirmar-se como tal, conforme podemos ler neste trecho de um discurso de Otávio Frias Filho, diretor de redação da Folha de S. Paulo: "O jornalismo, tal como procuraram praticá-lo, é um serviço de utilidade pública. Divulgar a verdade, estimular um exercício consciente da cidadania, iluminar o debate dos problemas coletivos --que outra atividade seria mais elogiável e necessária do que essa?" (FOLHA.COM, 2011). Interessante ressaltar o emprego da palavra "iluminar" no discurso, remetendo a pretensão de tornar mais claro os reais problemas da sociedade. Podemos ver também alguns dos princípios editoriais da Rede Globo:

Sem a democracia, a livre iniciativa e a liberdade de expressão, é impossível praticar o modelo de jornalismo de que trata este documento, e é imperioso defendê-lo de qualquer tentativa de controle estatal ou paraestatal. Os limites do jornalista e das empresas de comunicação são as leis do país, e a liberdade de informar nunca pode ser considerada excessiva. (G1, 2011, p. 25)

A empresa define ainda que os princípios fundamentais da informação que produzem devem ser a isenção, correção e agilidade. Aqui é interessante verificar: como ao afirmar que o jornalismo não pode ser controlado pelo estado ou organizações paraestatais, mas que está sujeito às leis do país, operaram uma separação do Estado das leis vigentes, como se um existisse independentemente do outro, quando na verdade são todos parte da mesma estrutura. Não podem negar a lei em vigor, mas negam o Estado que possuí entre suas atribuições a manutenção e a reforma da própria lei, a qual também é, portanto, resultante de uma disputa política. Em ambos os casos temos a defesa da autonomia da imprensa diante do Estado e o princípio de que a informação que produzem é necessária ao desenvolvimento da cidadania e da democracia.

Acreditamos que o fato de não ser possível identificar formas específicas de favorecimento e manipulação nos telejornais acompanhados na pesquisa pode ser reflexo dessa pretensão, mas não somente. Há que se considerar a trajetória passada desses telejornais, de envolvimento em questões polêmicas da manipulação da informação, que certamente influenciaram na condução de sua linha editorial posterior.

Não podemos, contudo, finalizar esta conclusão sem tocarmos em um ponto importante das eleições de 2010, que foi a utilização da internet, através dos blogs e redes sociais. Em tais meios, a comunicação ocorre frequentemente de maneira multidirecional, ou seja, os leitores não somente acessam a informação, mas podem deixar suas impressões e debatê-las diretamente com outros internautas. Com um esforço relativamente pequeno, qualquer pessoa com conhecimentos mínimos de informática e navegação na rede pode montar seu próprio blog, sem custos, iniciando a publicização de suas próprias reflexões e receber retornos de eventuais leitores. Mas, cumpre-nos aqui pensar em qual é o real impacto dessa nova ferramenta política, aventando algumas possibilidades em futuras pesquisas. Temos, de um lado, a utilização do espaço da rede por 
partidos políticos, que divulgam suas propostas, críticas aos adversários e até mesmo suas próprias interpretações sobre o noticiário. A campanha de Obama nos EUA, em 2008, utilizou a rede, não somente para divulgar a candidatura, mas para arrecadar recursos financeiros para a mesma. Porém, já em 2001, quando da deposição do então presidente das Filipinas, Joseph Estrada, a rede foi utilizada para espalhar milhares de mensagens de texto para celulares, convocando a população para as primeiras manifestações, com todos vestidos de preto (RHEINGOLD, 2003).

As mesmas observações, sobre o poder mobilizador das novas formas de comunicação, foi feita nos episódios conhecidos como "primavera árabe", que irromperam uma onda protestos por maior liberdade e democracia naqueles países. Trata-se de uma transformação, de uma revolução na forma de se comunicar e de fazer política ${ }^{18}$ ? Vários são os elementos que impõem limites a tais afirmações.

Primeiro trata-se de perceber que sem a existência de uma vontade previamente definida de mudança não será uma mensagem de texto que a gerará instantaneamente. Os jovens que saíram as ruas vestidos de preto no Brasil em 1992 não contavam ainda com tais recursos e as mobilizações foram realizadas por diversos dias, contribuindo para o posterior impeachment de Fernando Collor de Melo. Talvez o grande fator a ser considerado agora é a velocidade com que tais movimentos podem ser organizados e quando a velocidade se encontra com a vontade de mudança os eventos tomam maior dimensão.

Outro ponto a ser lembrado é a dificuldade de se contabilizar quem realmente está acompanhando as discussões na rede. Um eleitor definido em sua intenção de votar em certo candidato em 2010 dificilmente gastaria seu tempo lendo o blog do outro candidato. Não há também como termos a dimensão exata de quantas pessoas diferentes efetivamente acessam tais discussões na rede, uma vez que a mesma pessoa pode acessar vários sites diferentes com identificações diferentes e várias vezes.

Desse modo temos que considerar que talvez o maior papel da rede seja o de fortalecer as intenções de voto já existentes, de municiar os militantes com argumentos e críticas, muito mais do que provocar alterações nas intenções de voto.

Se for assim, estamos diante de um quadro que na verdade é muito semelhante ao que foi descrito ao longo deste artigo, no que refere as escolhas feitas pela população nas eleições e nas suas relações com aqueles que atuam produzindo e transmitindo informações, o que somente reforça a necessidade de estudos mais aprofundados nessa área. Esperamos, para o bem do fortalecimento de nossa democracia, que sejam os bilontras mencionados por Carvalho que estão deixando de ser a plateia que não acredita na seriedade do que assiste para tomarem o espetáculo em suas próprias mãos.

\footnotetext{
${ }^{18}$ Lembramos aqui do sentido de política no mundo grego, onde o uso correto das palavras diante da multidão reunida era considerado parte essencial da vivência daquela democracia (VERNANT, 1996).
} 


\section{Referências}

1. ADORNO, T., HORKHEIMER, M. Dialética do Iluminismo. Rio de Janeiro: Zahar, 1994.

2. AZEVEDO, Fernando Antônio. Imprensa, cobertura eleitoral e objetividade: a eleição de 2000 na capital paulista. Opin. Publica [online]. 2001, vol.7, n.2, pp. 182-201.

3. Mídia e democracia no Brasil: relações entre o sistema de mídia e o sistema político. Opin. Publica [online]. 2006, vol.12, n.1, pp. 88-113.

4.

O Senado nos editoriais dos jornais paulistas (2003 - 2004). Opin. Publica [online]. 2008, vol.14, n.1, pp. 173-204.

5. BARROS, Antonio Teixeira de. Jornalismo cidadão: informa ou deforma?. Ci. Inf. [online]. 2009, vol.38, n.1, pp. 142-144.

6. BAVARESCO, Agemir, KONZEN, Paulo Roberto. Cenários da liberdade de imprensa e opinião pública em Hegel. Kriterion [online]. 2009, vol.50, n.119, pp. 63-92.

7. BRETON, Philippe, PROULX, Serge. Sociologia da Comunicação. 2. ed. São Paulo: Loyola, 2006.

8. CAMPOS, Marcelo da Silveira. Mídia e Política: a construção da agenda nas propostas de redução da maioridade penal na Câmara dos Deputados. Opin. Publica [online]. 2009, vol.15, n.2, pp. 478-509.

9. CANCLINI, Néstor García. Cidades e cidadãos imaginados pelos meios de comunicação. Opin. Publica [online]. 2002, vol.8, n.1, pp. 40-53.

10. CARVALHO, Fátima Lampreia. Continuidade e inovação: conservadorismo e política da comunicação no Brasil. Rev. bras. Ci. Soc. [online]. 2000, vol.15, n.43, pp. 147-162.

11. CARVALHO, JoséMurilode. Os Bestializados - O Rio de Janeiro e a República que não Foi,

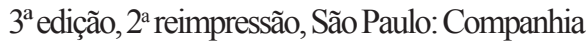
das Letras, 1996.
12. COIMBRA, Marcos. A mídia teve algum papel durante o processo eleitoral de 2006?. LIMA, Venício de. (org.). A Mídia nas Eleições de 2006. São Paulo: Perseu Abramo, 2007.

13. COSTA, Sergio. Movimentos sociais, democratização e a construção de esferas públicas locais. Rev. bras. Ci. Soc. [online]. 1997, vol.12, n.35.

14. DATAFOLHA. TV é meio mais usado pelo eleitor para se informar sobre a eleição. Datafolha Instituto de Pesquisas. 28 jul. 2010. Disponível em: $<$ http://datafolha.folha. uol.com.br/po/ver_po.php?session=1007> . Acesso em: 30 mar. 2011.

15. FERREIRA, Luiz Antonio. Intencionalidade, jornalismo opinativo e leitura. Interface (Botucatu) [online]. 2000, vol.4, n.6, pp. 187-192.

16. FIGUEIREDO, Rubens, COUTINHO, Ciro. A eleição de 2002. Opin. Publica [online]. 2003, vol.9, n.2, pp. 93-117.

17. FOLHA.COM. Otavio Frias Filho reafirma compromissos editoriais da Folha. Folha.com. 21 fev. 2011. Disponível em: <http://www1.folha.uol. com.br/folha90anos/879090-otavio-friasfilho-reafirma-compromissos-editoriaisda-folha.shtml>. Acesso em: 20 dez. 2011.

18. G1. Brasil tem mais TV do que geladeira, diz estudo. Globo.com. 18 abr. 2007. Disponível em: $<\underline{\text { http://g1.globo.com/Noticias/Economia }}$ Negocios/0, MUL23738-9356,00.html>. Acesso em: 30 mar. 2011.

19. Princípios editoriais das organizações globo. Globo.com. 2011. Disponível em: <http:/g1.globo.com/ principios-editoriais-das-organizacoesglobo.html\#definicao-do-jornalismo>. Acesso em: 20 dez. 2011.

20. GUARESCHI, Pedrinho Arcides, ROMANZINI, Lisie Polita, GRASSI, Lúcia Biavaschi. A "mercadoria" informação: um estudo sobre comerciais de TV e rádio. Paidéia (Ribeirão Preto) [online]. 2008, vol.18, n.41, pp. 567-580. 
21. KAMEL, Ali. O jornalismo. O Globo. 23 jan. 2007a, p. 07. Disponível em: <http://www. alikamel.com.br/upload/data/2007.01.23. pdf>. Acesso em: 15 jul. 2011.

22. Jornalismo e Objetividade. $\mathbf{O}$ Globo. 06 fev. 2007b, p. 07. Disponível em: $\quad<\underline{\text { http://www.alikamel.com.br/ }}$ upload/data/2007.02.06.pdf>. Acesso em: 15 jul. 2011.

23. LEITE, Márcia Pereira. Entre o individualismo e a solidariedade: dilemas da política e da cidadania no Rio de Janeiro. Rev. bras. Ci. Soc. [online]. 2000, vol.15, n.44, pp. 43-90.

24. LOURENCO, Luiz Claudio. Propaganda negativa: ataque versus votos nas eleições presidenciais de 2002. Opin. Publica [online]. 2009, vol.15, n.1, pp. 133-158.

25. MARQUES, Angela Cristina Salgueiro. Comunicação, mídia e processos de democracia local: estratégias de aproximação entre governo e cidadãos. Opin. Publica [online]. 2009, vol.15, n.1, pp. 107-132.

26. MARTÍN-BARBERO, Jesus. Mercado global e a influência dos meios de comunicação. São Paulo: 2003. Roda VivaTV Cultura, 2003. Disponível em: $<\underline{\text { http:// }}$ www.tvcultura.com.br/rodaviva/programa/ pgm0834>. Acesso em: 30 mar. 2011.

27. Dos meios às mediações: comunicação, cultura e hegemonia. Rio de Janeiro: UFRJ, 2003.

28. MATHEUS, Carlos Eduardo Meirelles. Muito Além do Cidadão Kane. Reino Unido: 1993. Channel 4, 1993.

29. MENASCHE, Renata. Os grãos da discórdia e o trabalho da mídia. Opin. Publica [online]. 2005, vol.11, n.1, pp. 169-191.

30. MIGUEL, Luís Felipe. Retrato de uma ausência: a mídia nos relatos da história política do Brasil. Rev. Bras. Hist. [online]. 2000, vol.20, n.39, pp. 191-199.
31. Representação política em 3-D: elementos para uma teoria ampliada da representação política. Rev. bras. Ci. Soc. [online]. 2003, vol.18, n.51, pp. 123-140.

32. Mídia e vínculo eleitoral: a literatura internacional e o caso brasileiro. Opin. Publica [online]. 2004, vol.10, n.1, pp. 91-111.

33. - Política em tempos de mídia.

Rev. bras. Ci. Soc. [online]. 2005, vol.20, n.58, pp. 197-199.

34. COUTINHO, Aline de Almeida. A crise e suas fronteiras: oito meses de "mensalão" nos editoriais dos jornais. Opin. Publica [online]. 2007, vol.13, n.1, pp. 97-123.

35. BIROLI, Flávia. Mídia e representação política feminina: hipóteses de pesquisa. Opin. Publica [online]. 2009, vol.15, n.1, pp. 55-81.

36. ROCHA, Maria Eduarda da Mota. O canto da sereia: notas sobre o discurso neoliberal na publicidade brasileira pós1990. Rev. bras. Ci. Soc. [online]. 2007 , vol.22, n.64, pp. 81-90.

37. RHEINGOLD, Howard. Smarts Mobs The Next Revolution. USA: Perseus, 2002.

38. RODRIGUES, Francisco Xavier Freire. Modernidade, disciplina e futebol: uma análise

39. sociológica da produção social do jogador de futebol no Brasil. Sociologias. Porto Alegre, ano $6, n^{\circ} 11$, jan/jun 2004, p. 260-299.

40. RUBIM, Antonio Albino Canelas. Novas configurações das eleições na idade mídia. Opin. Publica [online]. 2001, vol.7, n.2, pp. 168-181.

41. VERNANT, Jean-Pierre. As Origens do Pensamento Grego. 9 ed. Rio de Janeiro: Bertrand Brasil, 1996.

\section{Endereço para Correspondência:}

Prof. Dr. Vitor Barletta Machado

vitorbmach@yahoo.com.br

R. Vinte, 130, Jd. Veneza - Volta Redonda-RJ

CEP: 27285-330. 